\title{
The Natural Environment of Physical Activity and Perceived Stress: The Mediating Role of Specific Recovery Experiences
}

\author{
Julia Schmid $^{1 *}$, Lars Imbach ${ }^{1}$, Sandra Klaperski ${ }^{2}$ and Gorden Sudeck ${ }^{3}$ \\ ${ }^{1}$ Department of Sport Psychology and Research Methods, Institute of Sport Science, University of Bern, Bern, Switzerland, \\ ${ }^{2}$ Department of Psychology, Faculty of Social and Behavioural Sciences, University of Amsterdam, Amsterdam, Netherlands, \\ ${ }^{3}$ Department of Education \& Health Research, Institute of Sport Science, University of Tübingen, Tübingen, Germany
}

\section{OPEN ACCESS}

Edited by:

Selenia Di Fronso,

University of Studies G. d'Annunzio

Chieti and Pescara, Italy

Reviewed by:

Sarah Jakowski,

Ruhr University Bochum, Germany

Vacher Philippe,

Université de Bretagne

Occidentale, France

*Correspondence:

Julia Schmid

julia.schmid@ispw.unibe.ch

Specialty section:

This article was submitted to

Movement Science and Sport

Psychology,

a section of the journal

Frontiers in Sports and Active Living

Received: 07 May 2021

Accepted: 22 July 2021

Published: 16 August 2021

Citation:

Schmid J, Imbach L, Klaperski S and

Sudeck G (2021) The Natural

Environment of Physical Activity and

Perceived Stress: The Mediating Role

of Specific Recovery Experiences.

Front. Sports Act. Living 3:706467.

doi: 10.3389/fspor.2021.706467
Objective: The purpose of this study was to investigate a potential psychological mechanism of green exercise on perceived stress. More precisely, it was analyzed whether the relationship between the natural environment of physical activity and perceived stress was mediated by recovery experiences, namely by psychological detachment and relaxation. An ecological momentary assessment approach was used, meaning that specific recovery experiences were assessed directly in real-life situations and multiple times.

Materials and methods: Thirty five women and 27 men took part in the ecological momentary assessment study over seven days ( $M_{\text {age }}=32.30$ years, $S D=10.23,53 \%$ had a degree from a university or a university of applied science). If participants were involved in PA lasting at least 10 min on a given day, they had to answer questionnaires on the smartphone both prior to the activity and immediately afterwards. Perceived naturalness, psychological detachment and relaxation were assessed after physical activity events, whereas perceived stress was measured before and after each physical activity event. A two-level mediation analysis was conducted. The direct and indirect effect of perceived naturalness on perceived stress after engagement in physical activity was analyzed on the within- and between-person levels.

Results and conclusion: Results showed that the relaxation as a recovery experience served as mediator between perceived naturalness and perceived stress after engagement in physical activity, but only on a within-person level. This means that the more natural a given individual appraised the physical activity environment, the more relaxed he or she felt during physical activity $(\beta=0.322, p<0.0005)$. Furthermore the more relaxed the individual was, the less stress he or she perceived after exercising ( $\beta=-0.221, p<0.0005)$. The psychological detachment as a recovery experience in contrast, did not serve as mediator, neither at the within- and the between-person level. Considering the indirect effect of perceived naturalness on perceived stress and the importance of relaxation experiences, current findings suggest that research should put greater emphasis on examining the specific psychological mechanisms of green exercise to make even better use of its beneficial effects in the future.

Keywords: green exercise, stress regulation, ecological momentary assessment, restorative experiences, natural environment 


\section{INTRODUCTION}

Work is consistently being reported to be one of the main sources of stress in daily life (American Psychological Association, 2019). In Switzerland, $29.6 \%$ of all employees felt stressed at work in the year 2020. Just like in other Western nations, this number has increased over the last six years (Galliker et al., 2020; Health Safety Executive, 2020). This development is worrying, as numerous meta-analyses and reviews show that a high number of job stressors (e.g., high workload, intrapersonal conflicts) often lead to illnesses and poor mental well-being, particularly when job stressors persist over longer periods of time (Crawford et al., 2010; Nixon et al., 2011; Law et al., 2020). These negative impacts of job stressors can be reduced with recovery activities during non-working time (Sonnentag, 2018a). Physical activity (PA) has been shown to be a very effective recovery activity (see for a summary Sonnentag, 2018b), with about $60 \%$ of adults reporting that they exercise and do sports to reduce stress (Schmid et al., 2018). However, little is known about which settings or what types of activities are particularly effective (Klaperski et al., 2019).

In the past decades, there has been growing research interest in PA in natural environment, so-called "green exercise." It is hypothesized that direct exposure to nature (e.g., in parks, forests or by lakes) increases the positive effects PA has on mental well-being (Pretty, 2004). While a narrative review from 2011 found that green exercise produced a more favorable impact on mental well-being when compared to indoor exercise (Thompson Coon et al., 2011), more recent reviews show little or no added value (Lahart et al., 2019; Mnich et al., 2019). Overall, existing evidence is still limited and characterized by the heterogeneity of studies. Authors have identified several research gaps that need to be addressed.

A first important issue that future research should investigate are the underlying mechanisms of green exercise (Mnich et al., 2019). If we know which factors may promote mental well-being, they can be better targeted in studies and health promotion programs. Various theories in the field of environmental psychology have been proposed to explain the potential effect of nature, with the Stress Recovery Theory (SRT; Ulrich, 1983) and the Attention Restoration Theory (ART; Kaplan and Kaplan, 1989) being particularly prominent. SRT assumes that humans are programmed to react emotionally positively to natural settings and elements because these settings and elements are evolutionarily associated with safety and survival. This in turn, should reduce or buffer stress. Whereas, SRT focusses on affective benefits that may derive from nature, ART focusses on cognitive benefits. ART assumes that nature provides stimuli that attract involuntary, automatic attention. This effortless mode of attention allows individuals to recover from mental fatigue which occurs after performing cognitive tasks that require directed attention. Both theories highlight the negative impact of stress and suggest that nature-rich places are more likely to facilitate restoration or recovery experiences than built or urban environment (Joye and Dewitte, 2018). However, the theories differ with regard to the specific experiences they consider to be key in positively affecting mental well-being. Kaplan and Kaplan (1989) suggest, as asserted by their ART, that natural environments need to create a sense of "being away" to have a recovery effect. Concerning the SRT, Ulrich et al. (1991, p. 226) assume that natural settings generate a "mild, eyes-open form of relaxation response or wakeful, meditation-like state," which leads to their stress reducing effect. While there is only limited evidence on the role of these specific experiences of "being away" and relaxation in green exercise research, there has been a lot of research examining these concepts in the field of occupational health psychology: Sonnentag and Fritz (2007) identified psychological detachment and relaxation as two crucial experiences during off-job time that promote recovery from daily stressors at work.

Psychological detachment refers to the experience of "switching off." It is characterized by being physically away from the workplace (i.e., one does not engage in any work-related activities) and by mentally disengaging from work during leisure time (i.e., one does not think about work in one's free time). In contrast, relaxation refers to the positively-toned state of low activation (Sonnentag and Fritz, 2007). Meta-analytic evidence shows that both recovery experiences are associated with better mental well-being on a day-to-day level (Bennett et al., 2018). Consequently, it seems reasonable to hypothesize that psychological detachment and relaxation mediate the potential effect of green exercise on mental well-being by reducing the effects of stress. Yet only a few studies provide insights into this research topic to this day. For instance, Feuerhahn et al. (2014) demonstrated that the relation between PA and positive affect in the evening was explained by psychological detachment. However, in this study the natural environment of PA was not considered. Furthermore, Korpela et al. (2014) showed that the link between nature-based outdoor activities and well-being was mediated by a global measure of recovery experiences. Yet again, these research findings have limited transferability, because the study did not focus specifically on PA and detachment or relaxation. To the best of our knowledge, no study has yet examined the relationship between PA in a natural environment, psychological detachment, relaxation and perceived stress.

A second issue in existing green exercise research is that studies on short-term effects and mechanisms often use only a single bout of exercise, mainly being walking or running, and mostly in artificial laboratory conditions (Lahart et al., 2019; Mnich et al., 2019). Here, an ecological momentary assessment approach (EMA) may offer promising new insights. In EMA studies, features are measured immediately and multiple times in real-life situations, often by using smartphones (Dunton, 2017). Measuring features in real-life situations has the advantage that recovery experiences can be recorded as close as possible to the actual activity under natural conditions. The repeated measurements furthermore allow for the study of both intra-individual variations (within-person level) and interindividual variations (between-person level). This is important, as the mechanisms of green exercise on mental well-being can be different depending on which level is being examined. For example, a negative association between psychological detachment and perceived stress after PA on the withinperson level would mean that a given individual in different PA bouts experienced less stress if the activity allowed for 
distance from work. In contrast, the same negative link on the between-level would indicate that individuals who experienced a higher level of psychological detachment during PA on average would report lower stress levels afterwards. If the decomposition of within-person and between-person effects were ignored and only between-person effects were considered, an improper generalization of between-person effects could occur. The between-person relationship would be inappropriately generalized to intra-individual relationships between natural environment of PA, recovery experiences and perceived stress. Thus, if both levels of analysis are taken into account, the risk of results being misinterpreted can be minimized. The fact that this has rarely been done in existing studies might be one reason for the inconsistent findings in green exercise research (Thompson Coon et al., 2011; Lahart et al., 2019; Mnich et al., 2019).

Thus, the aim of this study is to examine whether the potential relationship between PA in a natural environment and perceived stress is mediated by recovery experiences, specifically by psychological detachment and relaxation. While recovery experiences in previous studies in this area were recorded retrospectively (e.g., in the evening, Feuerhahn et al., 2014) or in a general manner (Korpela et al., 2014), the present research will use an EMA approach and assess specific recovery experiences directly in the scenario and across multiple bouts of PA in a sample of Swiss working adults. A working population will be examined because work is a main source of stress and to test the role of psychological detachment from work. The present findings have the potential to optimize exercise recommendations to achieve the most beneficial health effects.

\section{METHODS}

\section{Sample}

Inclusion criteria for the study were that participants worked at least $80 \%$, were fluent in German, that they were between 20 and 59 years of age and that they engaged in exercise and sport activities sporadically or regularly (at least once a week). Furthermore, individuals were excluded if they were obese (BMI $\geq 30$ ), because body weight might influence (recovery) experiences during PA and should consequently be controlled for (Toft and Uhrenfeldt, 2015). Finally, top athletes were excluded from the study, because the study focused on non-competitive PA behavior. Participant recruitment took place via the health management of more than 20 different service companies in the sectors credit/insurance or information/communication and through personal contacts of study assistants. The final sample consists of 62 individuals, of which $56.5 \%$ were female. The average age was $M=32.30$ years $(S D=10.23$, range: 22-59 years). Fifty Three percent of participants indicated having a degree from a university or a university of applied science as their highest level of education. The average fulltime equivalent participants worked was $95.4 \%$. 35.5\% of the participants held a leadership position. Eighty percent of the participants did not have children. $8.1 \%$ of the participants reported at the beginning of the study that they habitually exercised $<75$ min per week and $91.9 \%$ exercised 75 min per week or more.

\section{Study Design and Procedure}

Participants who met the inclusion criteria and who were interested in participating in the study were individually invited to a face-to-face meeting or a phone call. There, they received information about the study goals and procedure. All participants gave their written informed consent and were free to decline participation. Afterwards, study assistants handed out a smartphone (Motorola Moto G5) on which the app "movisensXS" (Movisens GmbH, Karlsruhe, Germany) was installed. With this app, questionnaires can be implemented offline and from anywhere. All participants received detailed verbal instructions on how to answer the questionnaires in the app and answered sample items to become familiar with the app.

Basic sociodemographic information (e.g., age) was gathered via questionnaires before starting the EMA procedure. The EMA procedure for each participant lasted 7 days and took place sometime between the beginning of August and the end of October 2020. If participants were involved in PA lasting at least $10 \mathrm{~min}$ on a given day, they had to answer questionnaires on the smartphone both prior to the activity and afterwards (see Figure 1). It was emphasized that they needed to fill in the questionnaires as close in time to the PA session as possible (e.g., before showering or changing) and that they should not change their PA behavior because of the study. All participants received a definition of leisure-time PA to make clear when they had to complete the questionnaires (Fuchs et al., 2015).

As compensation, participants received a voucher for a swiss supermarket worth 35 Swiss francs (20 CHF for participation and another $15 \mathrm{CHF}$ for completing seven days). In addition, they received individual feedback on their PA behavior (a summary of their weekly exercise volume and estimated energy consumption) after finishing the study. The Ethics Committee of the University of Bern's Faculty of Human Sciences approved the study.

\section{Measures}

\section{Mode and Type of Physical Activity}

The mode of PA was assessed after PA using the classification schema of Strath et al. (2013). Participants were asked to indicate whether they had just engaged in (a) exercise or sport in leisure time, (b) physical activity for transport, (c) domestic physical activity, (d) occupational physical activity, or (e) others. Furthermore, individuals had to name the type of PA (e.g., jogging, cycling).

\section{Perceived Naturalness}

Naturalness was assessed after PA using a visual analog scale by Mackay and Neill (2010). In their quasi-experimental study, they found a negative association between perceived naturalness and post-exercise anxiety, which supports the validity of the scale (see also Klaperski et al., 2019). In the visual analog scale, participants had to indicate the PA environment's degree of naturalness. The scale ranged from 0 "artificial/urban" to 100 "natural." A skyline 


\title{
Seven days ecological momentary assessment \\ .
}

between August and October 2020

\begin{abstract}
Smartphone-based survey before each PA event:

- Perceived stress
\end{abstract}

(n)
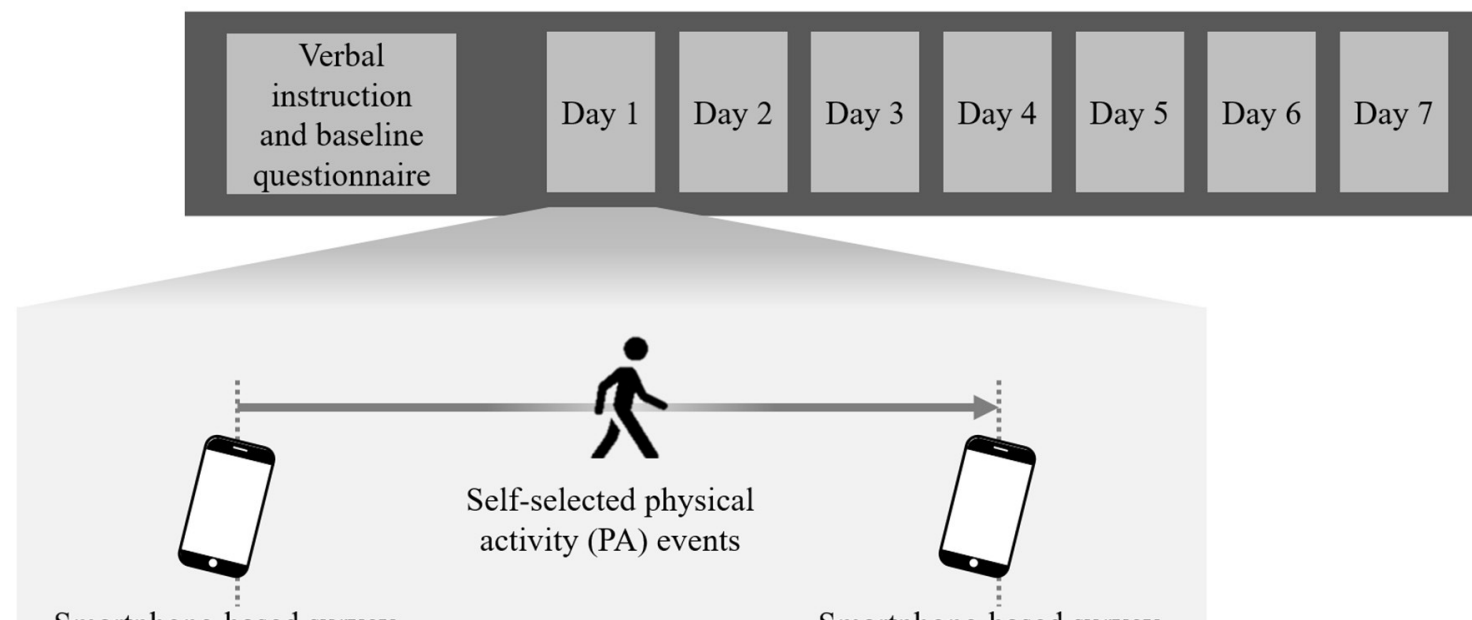

\begin{abstract}
- Perceived stress
- Recovery experiences
- Perceived naturalness
\end{abstract}
Smartphone-based survey after each PA event:

FIGURE 1 | Study procedure.

icon was shown at the artificial end of the scale and a forest icon was shown at the natural end of the scale.

\section{Recovery Experiences During PA: Psychological Detachment and Relaxation}

Psychological detachment and relaxation were assessed after PA with an adapted version of the recovery experience questionnaire (REQ) by Sonnentag and Fritz (2007). In the original REQ people are asked to rate recovery experiences in a general manner (item stem: "In my leisure-time..."). In order to capture recovery experiences situationally and with regard to PA, the original item stem was adapted to "During the PA event I have just carried out... " Of the original four items per subscale, those two were selected which had the highest loadings in the factor analysis (Sonnentag and Fritz, 2007; Chawla et al., 2020) and which simultaneously seemed appropriate in the PA context. Example items include "I forgot about work" (psychological detachment) and "I kicked back and relaxed" (relaxation). The response format was a 5-point scale from one "I do not agree at all" to 5 "I fully agree." The internal consistency of the subscales was rated satisfactory to good (psychological detachment: $r_{\text {within-person level }}$ $=0.77 ; r_{\text {between }- \text { person level }}=0.98$; relaxation: $r_{\text {within }- \text { person level }}=$ $0.52 ; r_{\text {between }}$-person level $\left.=0.73\right)$.

\section{Perceived Stress}

Perceived stress was assessed before and after PA with a visual analog scale widely used in research and clinical practice (Lesage et al., 2012). Existing studies have demonstrated its good reliability and sensitivity for assessing perceived stress caused by acutely distressing events. Furthermore, medium to high correlations with other stress questionnaires support the validity of the scale (Lesage et al., 2012). Participants had to indicate how stressed they felt at that moment. The response scale ranged from 0 "not stressed" to 100 "very stressed."

\section{Data Preparation and Analysis}

For the analyses, only sport and exercise activities in leisure time (e.g., hiking, soccer, yoga) and transportation related activities (e.g., walking or cycling to work) were considered. We excluded occupational PA, because the present study focuses on nonwork PA experiences. Furthermore, we excluded physically demanding off-job duties, such as cleaning, as research shows that they often deplete resources and consequently should not be associated with recovery experiences (Ginoux et al., 2021). A two-level mediation analysis was applied, which allows for the consideration of the hierarchical structure of the data. The multiple measures of naturalness, recovery experiences during PA and perceived stress define the lower level of the hierarchy (level 1). These components were nested within the subjects that defined the higher level of the hierarchy (level 2). Based on theoretical considerations and empirical findings, the model was controlled for perceived stress before PA (Bennett et al., 2018; Sonnentag, 2018a). In total, 62 participants engaged in 423 PA events. The analysis was done with MLmed, a SPSS macro 


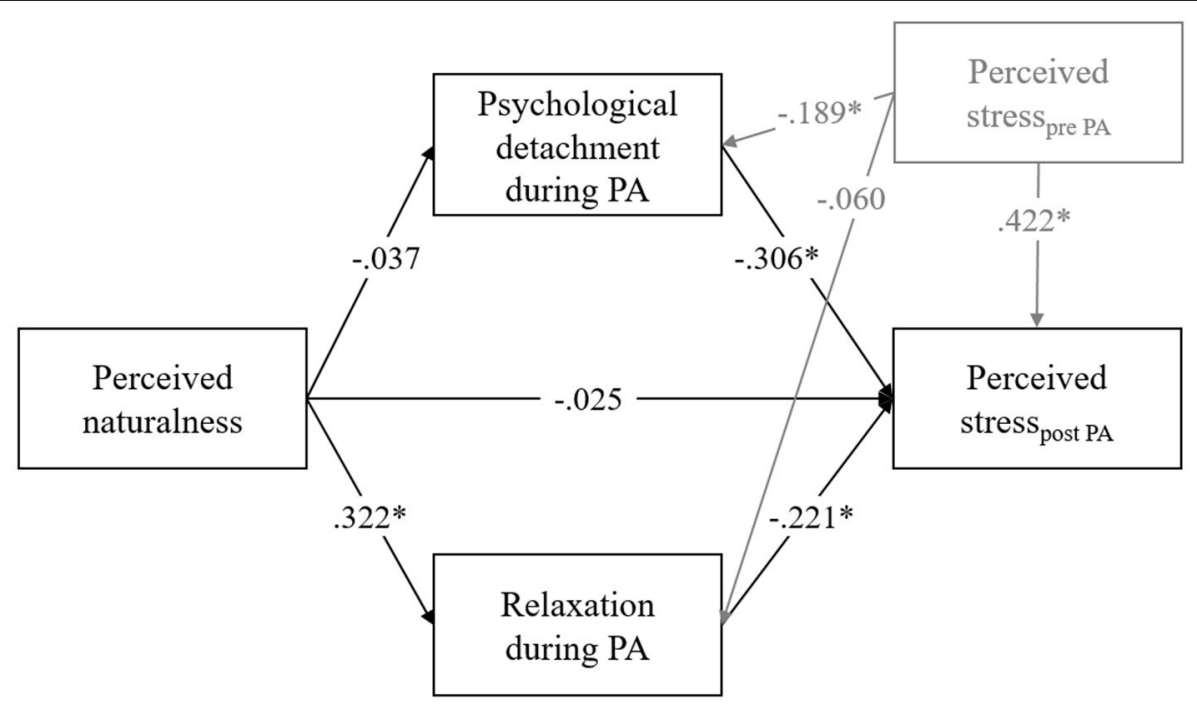

WITHIN-PERSON LEVEL

\section{BETWEEN-PERSON LEVEL}

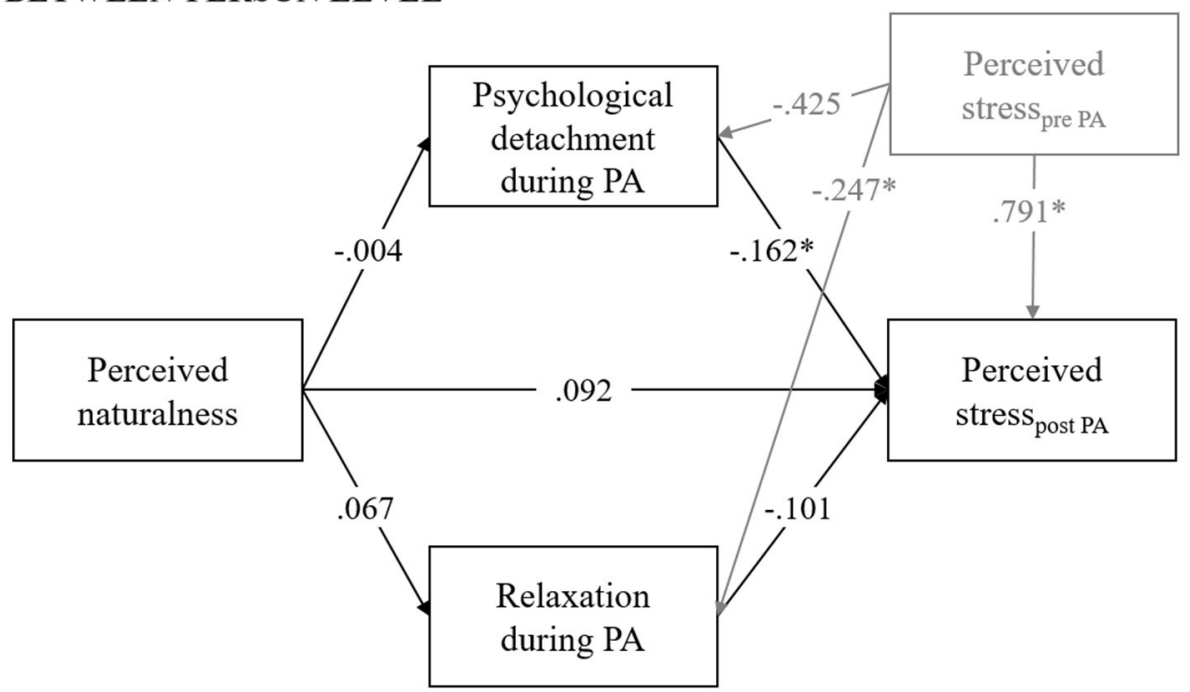

FIGURE 2 | Results of the two-level mediation analysis. All reported regression coefficients $\left(^{*}, p<0.05\right)$ are standardized estimates. For a better overview, control variables are shown in gray.

by Hayes and Rockwood (2020). A random-intercept-randomslope model $^{1}$ was calculated and estimated using a full maximum likelihood method. Indirect effects were tested for significance using Monte Carlo confidence intervals. All variables were centered around the group mean. The alpha level of the tests was set to $p<0.05$.

At the beginning, the entire data set was checked for multivariate outliers with Mahalonobis distance $(\chi 2$ at $p<$ 0.001; Tabachnick and Fidell, 2013). This led to three PA events

\footnotetext{
${ }^{1}$ Although slopes were principally specified as random effects in the model, four paths had to be fixed due to estimation problems. This applied to the following

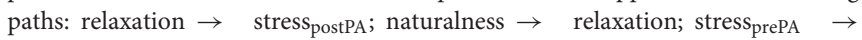
relaxation (see Figure 2).
}

being removed from the dataset. The proportion of missing values was $15 \%$ (392 of total 2,569 data points). However, as Little's test (Little and Rubin, 2020) was not significant, it could be assumed that values are missing completely at random $(\chi 2(30)=27.83, p=0.580)$. Consequently, missing values were imputed using the expectation-maximation algorithm (Tabachnick and Fidell, 2013).

\section{RESULTS}

\section{Descriptive Analysis}

Data analyses are based on $420 \mathrm{PA}$ events of 62 people. On average, 6.82 PA events per person were taken into account $(S D=3.99$, range: $2-22)$. Fifty five percent were exercise 
TABLE 1 | Descriptives of the study variables: Intraclass correlation coefficients (ICC), means $(M)$, variances $\left(\sigma^{2}\right)$ and correlations $\left({ }^{\star} p<0.05\right)$.

\begin{tabular}{|c|c|c|c|c|c|c|c|c|c|c|c|c|}
\hline \multirow[t]{3}{*}{ Variables [range] } & \multirow[t]{3}{*}{ ICC } & \multicolumn{6}{|c|}{ Between-person level } & \multicolumn{5}{|c|}{ Within-person level } \\
\hline & & \multirow[t]{2}{*}{$M$} & \multirow[t]{2}{*}{$\sigma^{2}$} & \multicolumn{4}{|c|}{ Correlations } & \multirow[t]{2}{*}{$\sigma^{2}$} & \multicolumn{4}{|c|}{ Correlations } \\
\hline & & & & 2. & 3. & 4. & 5. & & 2. & 3. & 4. & 5. \\
\hline $\begin{array}{l}\text { 1. Perceived naturalness } \\
\text { [1-100] }\end{array}$ & 0.361 & 49.86 & 1412.26 & -0.27 & -0.14 & 0.17 & 0.07 & 718.80 & $-0.21^{\star}$ & $-0.18^{\star}$ & -0.02 & $0.34^{*}$ \\
\hline $\begin{array}{l}\text { 2. Perceived stressprePA } \\
{[1-100]}\end{array}$ & 0.369 & 25.88 & 170.38 & - & $0.94^{\star}$ & $-0.46^{\star}$ & -0.19 & 279.58 & - & $0.52^{\star}$ & $-0.20^{\star}$ & $-0.13^{\star}$ \\
\hline $\begin{array}{l}\text { 3. Perceived stress } \\
\text { [1-100] }\end{array}$ & 0.425 & 18.77 & 131.74 & - & - & $-0.57^{*}$ & $-0.34^{\star}$ & 184.73 & - & - & $-0.48^{\star}$ & $-0.39^{\star}$ \\
\hline $\begin{array}{l}\text { 4. Psychological } \\
\text { detachment during PA } \\
{[1-5]}\end{array}$ & 0.261 & 3.96 & 0.28 & - & - & - & $0.56^{*}$ & 0.78 & - & - & - & $0.38^{\star}$ \\
\hline $\begin{array}{l}\text { 5. Relaxation during PA } \\
{[1-5]}\end{array}$ & 0.332 & 3.26 & 0.34 & - & - & - & - & 0.34 & - & - & - & - \\
\hline
\end{tabular}

and sport activities, such as running or playing football. Fourty five percent were daily activities for transport, such as cycling to work or walking to the grocery store. The average duration of one PA event was $64.21 \mathrm{~min}(S D=59.76$, range: $10 \mathrm{~min}-420 \mathrm{~min}$ ).

An overview of the descriptive statistics can be found in Table 1. To see whether study variables varied within individuals across recorded PA events, intra-class correlation coefficients needed to be subtracted from one. Values show that withinperson variation of the recovery experiences and perceived naturalness were moderate to high (naturalness: $64 \%$, relaxation: 67\%, psychological detachment: 73\%). Within-person variation of perceived stress after PA engagement (58\%) was slightly lower than before engagement in PA (63\%).

\section{Two-Level Mediation Model}

Figure 2 and Table 2 show that the relationships between the study variables differed depending on the level of the model: At the within-person level, perceived naturalness was positively associated with relaxation $(\beta=0.322, p<0.0005)$ but not with psychological detachment. This result indicates that the more natural a given person perceived the environment during multiple sessions of $\mathrm{PA}$, the more he or she relaxed. In contrast, at the between-person level, perceived naturalness was not associated with either recovery experience. Additionally, at the within-person level, both psychological detachment $(\beta=$ $-0.306, p<0.0005)$ and relaxation during PA $(\beta=-0.221, p<$ $0.0005)$ were negatively linked with perceived stress after PA. This means that the more a given individual distanced from work or the more he/she relaxed during multiple sessions of PA, the less stress he or she perceived. On a between-person level, however, only psychological detachment was negatively associated with perceived stress after PA $(\beta=-0.162, p=0.018)$ : Individuals who on average experienced a higher level of detachment during PA perceived less stress after PA.

Both on the within person- and the between person-levels, no evidence for direct effects were found from perceived naturalness on perceived stress after PA. However, the within personlevel model revealed a small indirect effect between perceived naturalness and perceived stress after PA via relaxation. This indirect path reached statistical significance $(\beta=-0.07, B$ $=-0.04$ [CI 95\%: $-0.059 ;-0.018]$ ), while the other indirect pathway did not.

\section{DISCUSSION}

The present study aimed to investigate whether the relationship between perceived naturalness and perceived stress after PA was mediated by specific recovery experiences. This research expands upon previous studies by examining a potential psychological mechanism of green exercise. By investigating psychological detachment and relaxation, we focused on two recovery experiences that have previously only been vaguely addressed in prominent theories in the field of green exercise (Ulrich, 1983; Kaplan and Kaplan, 1989), but that have been intensively researched in occupational health psychology (Bennett et al., 2018). In the present research, self-reports were collected multiple times from individuals, proximal to the time and place PA occurred. Such an EMA approach has recently been identified as promising for future green exercise research (Mnich et al., 2019), because it more likely captures phenomena that vary over time or space compared to traditional cross-sectional, retrospective and summary methods.

As hypothesized, the relaxation as a recovery experience served as mediator in this study, but only on a within-person level. The more natural a given individual rated the PA setting, the more relaxed he or she felt during PA. In turn, the more relaxed the individual was, the less stress he or she perceived after PA. However, in contrast to our assumptions, psychological detachment did not serve as mediator, neither at the withinnor the between-person levels. Overall, the study shows that the associations between the study variables was different depending on which level of analysis was being considered. An indirect effect of perceived naturalness on perceived stress after PA via 
TABLE 2 | Results of the two-level mediation analysis: unstandardized regression coefficients ( $\left.{ }^{*}, p<0.05\right)$, standard errors (SE) with lower and upper bounds of the convidence interval.

\begin{tabular}{|c|c|c|c|c|c|c|}
\hline Paths & $B$ & $S E$ & $t$ & $p$ & Lower bound & Upper bound \\
\hline Perceived stress postPA intercept & $18.84^{\star}$ & 6.13 & 3.07 & $<0.0005$ & 6.56 & 31.11 \\
\hline Psychological detachment intercept & $4.41^{\star}$ & 0.25 & 17.54 & $<0.0005$ & 3.91 & 4.91 \\
\hline Relaxation intercept & $3.44^{*}$ & 0.17 & 20.67 & $<0.0005$ & 3.12 & 3.77 \\
\hline \multicolumn{7}{|l|}{ Within-person level } \\
\hline Perceived naturalness $\rightarrow$ Perceived stresspostPA & -0.01 & 0.02 & -0.55 & 0.59 & -0.06 & 0.03 \\
\hline Perceived naturalness $\rightarrow$ Psychological detachment & 0.00 & 0.00 & -0.57 & 0.57 & -0.01 & 0.00 \\
\hline Psychological detachment $\rightarrow$ Perceived stress postPA & $-4.72^{*}$ & 0.77 & -6.15 & $<0.0005$ & -6.27 & -3.17 \\
\hline Perceived naturalness $\rightarrow$ Relaxation & $0.01^{*}$ & 0.00 & 5.08 & $<0.0005$ & 0.01 & 0.01 \\
\hline Relaxation $\rightarrow$ Perceived stresspostPA & $-3.61^{*}$ & 0.75 & -4.82 & $<0.0005$ & -5.09 & -2.14 \\
\hline Perceived stressprePA $\rightarrow$ Perceived stresspostPA & $0.34^{*}$ & 0.04 & 8.43 & $<0.0005$ & 0.26 & 0.43 \\
\hline Perceived stress $_{\text {prePA }} \rightarrow$ Psychological detachment & $-0.01^{*}$ & 0.00 & -3.35 & $<0.0005$ & -0.02 & 0.00 \\
\hline Perceived stress prePA $\rightarrow$ Relaxation & 0.00 & 0.00 & -0.95 & 0.34 & -0.01 & 0.00 \\
\hline \multicolumn{7}{|l|}{ Between-person level } \\
\hline Perceived naturalness $\rightarrow$ Perceived stresspostPA & 0.05 & 0.03 & 1.60 & 0.11 & -0.01 & 0.12 \\
\hline Perceived naturalness $\rightarrow$ Psychological detachment & 0.00 & 0.00 & -0.03 & 0.97 & -0.01 & 0.01 \\
\hline Psychological detachment $\rightarrow$ Perceived stress postPA & $-3.52^{*}$ & 1.38 & -2.56 & 0.01 & -6.27 & -0.77 \\
\hline Perceived naturalness $\rightarrow$ Relaxation & 0.00 & 0.00 & 0.87 & 0.38 & 0.00 & 0.01 \\
\hline Relaxation $\rightarrow$ Perceived stresspostPA & -1.98 & 1.21 & -1.64 & 0.11 & -4.39 & 0.43 \\
\hline Perceived stress $_{\text {prePA }} \rightarrow$ Perceived stress $_{\text {postPA }}$ & $0.70^{*}$ & 0.05 & 12.72 & $<0.0005$ & 0.59 & 0.80 \\
\hline Perceived stress $_{\text {prePA }} \rightarrow$ Psychological detachment & $-0.02^{*}$ & 0.01 & -3.29 & $<0.0005$ & -0.03 & -0.01 \\
\hline Perceived stressprePA $\rightarrow$ Relaxation & $-0.01^{*}$ & 0.00 & -3.33 & $<0.0005$ & -0.02 & 0.00 \\
\hline
\end{tabular}

relaxation could only be observed on a within-person level, where multiple PA events are considered as experienced within an individual. Thus, it seems to be a situational mechanism rather than a general one.

Our study results did not support Kaplan and Kaplan's (1989) assumption that vegetation-rich settings create a sense of "being away," which mediates the effect of naturalness on wellbeing. In line with the meta-analytic findings of Bennett et al. (2018), psychological detachment was associated with low stress after PA. However, psychological detachment was not linked to the naturalness of the environment of PA at either level of analysis. This finding might merely imply that the engagement in PA behavior is relevant to achieve detachment from work (Feuerhahn et al., 2014), and that there is no additional gain from a vegetation-rich environment. This would mean that taking an active "time-out" from work is in itself sufficient to recover from stress, a conclusion which has also been drawn in previous studies (Bahrke and Morgan, 1978). It is also possible that it is not necessarily the PA setting that influences psychological detachment, but rather more so the activity type. Fuchs and Klaperski (2018), for instance, suggest that activities which require being in the "here and now" as well as a deep involvement in the current action (e.g., climbing or game sports) prevent rumination or worry about hassles and therefore allow for mental distance from work. This assumption is supported by a recent quasi-experimental study in which it was demonstrated that bouldering facilitated mindfulness (e.g., being present) more when compared to a fitness training session (Wheatley, 2021).

\section{Limitations and Future Directions}

There are some limitations in this study that can lead to future research opportunities. Firstly, participants were mostly active, middle-aged and well-educated workers from the service sector. This relatively homogeneous sample limits the generalizability of the findings. Future research should explore whether the psychological mechanism observed in this study also appears in other occupational groups and professional contexts (Sonnentag et al., 2017). For instance, it can be assumed that people with physically demanding outdoor jobs (e.g., gardeners) experience less relaxation during leisure time PA in a natural environment than people with more cognitively demanding indoor jobs (e.g., administrative employees). Assessing different types of pre- and post-exercise recovery states and detachment (e.g., emotional, cognitive, or physical) could shed more light on these type of matching questions (see also Balk et al., 2017). Secondly, this study focused on perceived stress as an important determinant for well-being, yet well-being itself was not assessed. Although the amount of perceived stress seems to be particularly relevant in the work setting, future studies may assess affective wellbeing based on a dimensional approach (e.g., vigor and fatigue; Bennett et al., 2018). This would make it easier to compare the findings with existing research from the field of green exercise and occupational health psychology. Thirdly, the present research was limited to two specific recovery experiences as mediators. Psychological detachment and relaxation were chosen based on key assumptions of the ART, SRT (Ulrich, 1983; Kaplan and Kaplan, 1989) and on existing research in the field 
of occupational health psychology (Sonnentag and Fritz, 2007; Bennett et al., 2018). However, future research should investigate the impact of further mediators, but also moderators. An additional mediator might be, for example, "mind wandering." Mind wandering is defined as thinking unrelated to the ongoing task (Smallwood and Schooler, 2015) and mentally moving hither and thither without a fixed course or certain aim (Christoff et al., 2016). One can hypothesize that subtly fascinating natural environments (e.g., clouds) support mind wandering (Kaplan and Kaplan, 1989; Williams et al., 2018) and this in turn reduces stress (Miś and Kowalczyk, 2020). Potential moderators may be an individual's habitual environment, and representations and expectations of green exercise. A person who lives and works in an urban neighborhood could experience physical exercise in green surroundings as well as the naturalness of an environment differently than a person living and working in a rural environment. Green exercise could be experienced as a strong contrast and therefore enhance the effect of PA on stress, possibly also based on neurological differences (e.g., Lederbogen et al., 2011). Furthermore, an individual's goals for PA (e.g., Schmid et al., 2018) could be considered as possible moderators, as studies showed that such motivational aspects influence the effect of PA on affective well-being (e.g., Jeckel and Sudeck, 2018). Fourthly, data collection in this study took place over three months. While some participants took part during more summer-like weather conditions in August, other participants had more fall-like conditions in October. These different seasons (different temperatures, colors) may have influenced the findings. In line with this, Bloom et al. (2017) found that the experience of detachment and relaxation during a park walk differed in spring and fall. Fifth, the present analyses are based solely on self-reported data. Ideally, future studies should assess leisuretime PA and its natural environment in an objective way (e.g., with accelerometers and portable global positioning system data). Such complementary analyses might help to get a deeper understanding of PA's impact on stress and recovery. Finally, it cannot be ruled out that the measure of perceived stress before PA was already influenced by natural settings. It is possible, for example, that people were already impacted by rich vegetation while being on their way to green space. Research shows that even a short view of natural elements can provide psychological benefits (Lee et al., 2015).

\section{CONCLUSION}

This study provides new insights into the psychological mechanisms which might underlie the positive effects green exercise has on stress levels and mental well-being. It shows that being active in natural settings further increases the benefits of PA on perceived stress, by altering relaxation on a within-person level. Thus, being active within a vegetation-rich environment may be an effective way to calm down. Overall, the current findings suggest that research should put greater emphasis on examining the specific psychological mechanisms of green exercise to make even better use of its beneficial effects in the future. Furthermore, result patterns highlight the importance of using a multilevel approach in green exercise research.

\section{DATA AVAILABILITY STATEMENT}

The raw data supporting the conclusions of this article will be made available by the authors, without undue reservation.

\section{ETHICS STATEMENT}

The studies involving human participants were reviewed and approved by The Ethics Committee of the University of Bern's Faculty of Human Sciences. The patients/participants provided their written informed consent to participate in this study.

\section{AUTHOR CONTRIBUTIONS}

JS, SK, and GS contributed to the conception and design of the study. JS and LI acquired the data. JS and LI performed statistical analysis. JS wrote and drafted the manuscript. JS, LI, SK, and GS contributed to data analysis and interpretation. JS, LI, SK, and GS critically reviewed initial versions of the manuscript. All authors revised the manuscript critically for important intellectual content, as well as read and approved the final manuscript. All authors contributed to the article and approved the submitted version.

\section{FUNDING}

This study was partly supported by the Faculty of Human Sciences at the University of Bern. It funded the smartphones used in the study.

\section{ACKNOWLEDGMENTS}

A special thank goes to Jacqueline Konyo and Manuel Hoffmann for their assistance with data collection. Furthermore, we thank Markus Reichert (Central Institute of Mental Health, Mannheim, Germany) for his advice regarding the design of the study and Jürg Schmid (Institute of Sport Science, University of Bern) for his advice regarding data analysis.

\section{REFERENCES}

American Psychological Association (2019). Stress in America: Stress and Current Events. Stress in America Survey. Worcester, MA: American Psychological Association.

Bahrke, M. S., and Morgan, W. P. (1978). Anxiety reduction following exercise and meditation. Cogn. Ther. Res. 2, 323-333. doi: 10.1007/BF011 72650

Balk, Y. A., Jonge, J., de, Oerlemans, W. G., and Geurts, S. A. (2017). Testing the triple-match principle among dutch elite athletes: a day-level study on 
sport demands, detachment and recovery. Psychol. Sport Exerc. 33, 7-17. doi: 10.1016/j.psychsport.2017.07.006

Bennett, A. A., Bakker, A. B., and Field, J. G. (2018). Recovery from work-related effort: a meta-analysis. J. Organ. Behav. 39, 262-275. doi: 10.1002/job.2217

Bloom, J., de, Sianoja, M., Korpela, K., Tuomisto, M., Lilja, A., Geurts, S., et al. (2017). Effects of park walks and relaxation exercises during lunch breaks on recovery from job stress: two randomized controlled trials. J. Environ. Psychol. 51, 14-30. doi: 10.1016/j.jenvp.2017.03.006

Chawla, N., MacGowan, R. L., Gabriel, A. S., and Podsakoff, N. P. (2020). Unplugging or staying connected? Examining the nature, antecedents, and consequences of profiles of daily recovery experiences. J. Appl. Psychol. 105, 19-39. doi: 10.1037/apl0000423

Christoff, K., Irving, Z. C., Fox, K. C. R., Spreng, R. N., and Andrews-Hanna, J. R. (2016). Mind-wandering as spontaneous thought: a dynamic framework. Nat. Rev. Neurosci. 17, 718-731. doi: 10.1038/nrn.2016.113

Crawford, E. R., Lepine, J. A., and Rich, B. L. (2010). Linking job demands and resources to employee engagement and burnout: A theoretical extension and meta-analytic test. J. Appl. Psychol. 95, 834-848. doi: 10.1037/a0019364

Dunton, G. F. (2017). Ecological momentary assessment in physical activity research. Exerc. Sport Sci. Rev. 45, 48-54. doi: 10.1249/JES.00000000000 00092

Feuerhahn, N., Sonnentag, S., and Woll, A. (2014). Exercise after work, psychological mediators, and affect: a day-level study. Eur. J. Work Organ. Psychol. 23, 62-79. doi: 10.1080/1359432X.2012.709965

Fuchs, R., and Klaperski, S. (2018). "Stressregulation durch Sport und Bewegung," in Handbuch Stressregulation und Sport, eds R. Fuchs, and M. Gerber (Berlin: Springer), 205-226. doi: 10.1007/978-3-662-49322-9_9

Fuchs, R., Klaperski, S., Gerber, M., and Seelig, H. (2015). Messung der Bewegungs- und Sportaktivität mit dem BSA-Fragebogen: Eine methodische Zwischenbilanz [Measurement of physical activity and sport activity with the BSA questionnaire]. Zeitschrift für Gesundheitspsychologie 23, 60-76. doi: 10.1026/0943-8149/a000137

Galliker, S., Igic, I., Elfering, A., Semmer, N., Brunner, B., Dosch, S., et al. (2020). Job-Stress-Index 2020. Kennzahlen zum Stress bei Erwerbstätigen in der Schweiz: Faktenblatt 48. Bern: Gesundheitsförderung Schweiz.

Ginoux, C., Isoard-Gautheur, S., and Sarrazin, P. (2021). "What did you do this weekend?" relationships between weekend activities, recovery experiences, and changes in work-related well-being. Appl. Psychol. Health Well Being. doi: 10.1111/aphw.12272. [Epub ahead of print].

Hayes, A. F., and Rockwood, N. J. (2020). Conditional process analysis: Concepts, computation, and advances in the modeling of the contingencies of mechanisms. Am. Behav. Sci. 64, 19-54. doi: 10.1177/00027642198 59633

Health and Safety Executive (2020). Work-Related Stress, Anxiety or Depression Statistics in Great Britain. Health and Safety Executive.

Jeckel, S., and Sudeck, G. (2018). Sport activities in daily routine: situational associations between individual goals, activity characteristics and affective well-being. Ger. J. Exerc. Sport Res. 48, 26-39. doi: 10.1007/s12662-017-0469-9

Joye, Y., and Dewitte, S. (2018). Nature's broken path to restoration. A critical look at attention restoration theory. J. Environ. Psychol. 59, 1-8. doi: 10.1016/j.jenvp.2018.08.006

Kaplan, R., and Kaplan, S. (1989). The Experience of Nature: A Psychological Perspective. Cambridge: Cambridge University Press.

Klaperski, S., Koch, E., Hewel, D., Schempp, A., and Müller, J. (2019). Optimizing mental health benefits of exercise: the influence of the exercise environment on acute stress levels and well-being. Mental Health Prev. 15:200173. doi: 10.1016/j.mhp.2019.200173

Korpela, K. K., Borodulin, K., Neuvonen, M., Paronen, O., and Tyrväinen, L. (2014). Analyzing the mediators between nature-based outdoor recreation and emotional well-being. J. Environ. Psychol. 37, 1-7. doi: 10.1016/j.jenvp.2013.11.003

Lahart, I., Darcy, P., Gidlow, C., and Calogiuri, G. (2019). The effects of green exercise on physical and mental wellbeing: a systematic review. Int. J. Environ. Res. Public Health 16:1352. doi: 10.3390/ijerph16081352

Law, P. C. F., Too, L. S., Butterworth, P., Witt, K., Reavley, N., and Milner, A. J. (2020). A systematic review on the effect of work-related stressors on mental health of young workers. Int. Arch. Occup. Environ. Health 93, 611-622. doi: 10.1007/s00420-020-01516-7
Lederbogen, F., Kirsch, P., Haddad, L., Streit, F., Tost, H., Schuch, P., et al. (2011). City living and urban upbringing affect neural social stress processing in humans. Nature 474, 498-501. doi: 10.1038/nature10190

Lee, K. E., Williams, K. J., Sargent, L. D., Williams, N. S., and Johnson, K. A. (2015). 40-second green roof views sustain attention: the role of micro-breaks in attention restoration. J. Environ. Psychol. 42, 182-189. doi: 10.1016/j.jenvp.2015.04.003

Lesage, F. X., Berjot, S., and Deschamps, F. (2012). Clinical stress assessment using a visual analogue scale. Occup. Med. 62, 600-605. doi: 10.1093/occmed/kqs140

Little, R. J. A., and Rubin, D. B. (2020). Statistical Analysis With Missing Data, 3rd Edn. New York, NY: John Wiley and Sons. doi: 10.1002/9781119482260

Mackay, G. J., and Neill, J. T. (2010). The effect of "green exercise" on state anxiety and the role of exercise duration, intensity, and greenness: a quasi-experimental study. Psychol. Sport Exerc. 11, 238-245. doi: 10.1016/j.psychsport.2010.01.002

Miś, M., and Kowalczyk, M. (2020). Mind-wandering during long-distance running and mood change. The role of working memory capacity and temporal orientation of thoughts. Int. J. Sport Exerc. Psychol. 1-19. doi: 10.1080/1612197X.2020.1766538

Mnich, C., Weyland, S., Jekauc, D., and Schipperijn, J. (2019). Psychosocial and physiological health outcomes of green exercise in children and adolescents-a systematic review. Int. J. Environ. Res. Public Health 16:4266. doi: 10.3390/ijerph16214266

Nixon, A. E., Mazzola, J. J., Bauer, J., Krueger, J. R., and Spector, P. E. (2011). Can work make you sick? A meta-analysis of the relationships between job stressors and physical symptoms. Work Stress 25, 1-22. doi: $10.1080 / 02678373.2011 .569175$

Pretty, J. (2004). How nature contributes to mental and physical health. Spirituality Health Int. 5, 68-78. doi: 10.1002/shi.220

Schmid, J., Gut, V., Conzelmann, A., and Sudeck, G. (2018). Bernese motive and goal inventory in exercise and sport: validation of an updated version of the questionnaire. PLoS ONE 13:e0193214. doi: 10.1371/journal.pone.0193214

Smallwood, J., and Schooler, J. W. (2015). The science of mind wandering: empirically navigating the stream of consciousness. Annu. Rev. Psychol. 66, 487-518. doi: 10.1146/annurev-psych-010814-015331

Sonnentag, S. (2018a). Job-Stress Recovery: Core Findings, Future Research Topics, and Remaining Challenges. Work Science Center Thinking Forward Report Series. Atlanta, GA: Georgia Institute of Technology.

Sonnentag, S. (2018b). The recovery paradox: portraying the complex interplay between job stressors, lack of recovery, and poor well-being. Res. Organ. Behav. 38, 169-185. doi: 10.1016/j.riob.2018.11.002

Sonnentag, S., and Fritz, C. (2007). The recovery experience questionnaire: development and validation of a measure for assessing recuperation and unwinding from work. J. Occup. Health Psychol. 12, 204-221. doi: 10.1037/1076-8998.12.3.204

Sonnentag, S., Venz, L., and Casper, A. (2017). Advances in recovery research: what have we learned? What should be done next? J. Occup. Health Psychol. 22, 365-380. doi: 10.1037/ocp0000079

Strath, S. J., Kaminsky, L. A., Ainsworth, B. E., Ekelund, U., Freedson, P. S., Gary, R. A., et al. (2013). Guide to the assessment of physical activity: clinical and research applications. A scientific statement from the American heart association. Circulation 128, 2259-2279. doi: 10.1161/01.cir.0000435708.67487.da

Tabachnick, B. G., and Fidell, L. S. (2013). Using Multivariate Statistics, 6th Edn. London: Pearson Education.

Thompson Coon, J., Boddy, K., Stein, K., Whear, R., Barton, J., and Depledge, M. H. (2011). Does participating in physical activity in outdoor natural environments have a greater effect on physical and mental wellbeing than physical activity indoors? A systematic review. Environ. Sci. Technol. 45, 1761-1772. doi: 10.1021/es102947t

Toft, B. S., and Uhrenfeldt, L. (2015). The lived experiences of being physically active when morbidly obese: a qualitative systematic review. Int. J. Qual. Stud. Health Well Being 10:28577. doi: 10.3402/qhw.v10.28577

Ulrich, R. S. (1983). "Aesthetic and affective response to natural environment," in Behavior and the Natural Environment, eds I. Altman and J. F. Wohlwill (Berlin: Springer), 85-125. doi: 10.1007/978-1-4613-35 39-9_4

Ulrich, R. S., Simons, R. F., Losito, B. D., Fiorito, E., Miles, M. A., and Zelson, M. (1991). Stress recovery during exposure to natural and urban 
environments. J. Environ. Psychol. 11, 201-230. doi: 10.1016/S0272-4944(05)8 0184-7

Wheatley, K. A. (2021). Exploring the relationship between mindfulness and rockclimbing: a controlled study. Curr. Psychol. doi: 10.1007/s12144-021-01593-y. [Epub ahead of print].

Williams, K. J., Lee, K. E., Hartig, T., Sargent, L. D., Williams, N. S., and Johnson, K. A. (2018). Conceptualising creativity benefits of nature experience: attention restoration and mind wandering as complementary processes. J. Environ. Psychol. 59, 36-45. doi: 10.1016/j.jenvp.2018.08.005

Conflict of Interest: The authors declare that the research was conducted in the absence of any commercial or financial relationships that could be construed as a potential conflict of interest.
Publisher's Note: All claims expressed in this article are solely those of the authors and do not necessarily represent those of their affiliated organizations, or those of the publisher, the editors and the reviewers. Any product that may be evaluated in this article, or claim that may be made by its manufacturer, is not guaranteed or endorsed by the publisher.

Copyright (๑) 2021 Schmid, Imbach, Klaperski and Sudeck. This is an open-access article distributed under the terms of the Creative Commons Attribution License (CC $B Y)$. The use, distribution or reproduction in other forums is permitted, provided the original author(s) and the copyright owner(s) are credited and that the original publication in this journal is cited, in accordance with accepted academic practice. No use, distribution or reproduction is permitted which does not comply with these terms. 